\title{
Working with "Others": Developing Sustainability Skills in the First Year Engineering Classroom
}

Faculty of Applied Science, University of British Columbia

Susan Nesbit*, Naoko Ellis, Pete Ostafichuk

*Corresponding Author nesbit@civil.ubc.ca

\begin{abstract}
While engineering education excels at training students to solve well-defined and highly structured problems, it struggles to support the development of students' abilities to address highly complex, ill-structured, and contested engineering problems that lack in definite solutions, where engineers are called on to work with non-engineers in a transdisciplinary environment. The challenge for engineering educators is to develop and teach constructively aligned curricula aimed at developing transdisciplinary skills so that, as practitioners, graduating engineering students contribute to addressing these types of problems within transdisciplinary environments.

Efforts are underway in many institutions to close the gap between the transdisciplinary needs in practice and current engineering curricula. At the University of British Columbia (UBC), a team of faculty members and engineering practitioners have recently developed and are teaching a design-focused engineering course to all first year students. In this paper we, a subset of UBC's teaching team, present the argument for teaching skills to engineering students that support transdisciplinary. We summarize the definitions of these skills found in the literature, and we speculate that the development of one aspect of transdisciplinary is related to personal development. Specifically, we hypothesize that systems thinking is correlated to metacognition. We describe an experimental strategy for testing the hypothesis within a first year engineering program, then we present and discuss preliminary test results.
\end{abstract}

Keywords: First year, design courses, sustainability, transdisciplinarity, metacognition.

\section{INTRODUCTION}

Engineering sustainability problems relating to resource scarcity, climate change, and other multi-scale issues, are characterized by Lonngren et al. [14,15] and others as highly complex, ill-structured, contested, and lacking in definite solutions. Such "Wicked Sustainability Problems" (WSPs) challenge engineers to work with people possessing varied ways of thinking and doing [24]. Transdisciplinarity is proposed as an approach by which stakeholders, including engineers, successfully address and manage WSPs $[2,6]$. This approach involves mutual learning and a shared search for answers among problem stakeholders. It rejects the idea that knowledge must always be segmented into disciplinary "silos" and acknowledges that expertise comes in many forms. The challenge for engineering educators is to develop and teach constructively aligned curricula enabling engineering students to contribute to addressing these types of problems in transdisciplinary environments.

The University of British Columbia's first year engineering program has recently been redeveloped and now includes a strong focus on the introduction to design, including aspects of sustainability, as described elsewhere $[7,22]$. As part of the continual improvement of this new curriculum, we, a subset of the first year engineering teaching team, aim to enhance the opportunities for first year students to improve their novice-level sustainability skills. Here, we frame these skills in terms of transdisciplinarity because of the gap between the transdisciplinary needs in practice and the current engineering curricula which focuses on training students to solve well-defined problems.

\subsection{Transdisciplinary Skills}

Transdisciplinarity can be defined as a problemsolving approach that acknowledges complexity, social accountability, mutual learning, and the co-creation of knowledge [1]. Several critical characteristics of individuals who successfully navigate transdisciplinary situations are summarized in Table 1.

Table 1: Transdisciplinary Traits Described in the Literature

\begin{tabular}{|c|l|}
\hline Author & \multicolumn{1}{|c|}{ Transdisciplinary Characteristics } \\
\hline & $\begin{array}{l}\text { - a belief in the existence of different } \\
\text { levels of reality governed by different } \\
\text { types of logic, } \\
\text { - absolute respect for the collective, } \\
\text { - openness toward myth and religions, } \\
\text {-rigor in argument, } \\
\text { - openness to and acceptance of the }\end{array}$ \\
\hline
\end{tabular}

CEEA17; Paper 094

University of Toronto; June 4 - 7, 2017
-1 of $8-$ 


\begin{tabular}{|c|c|}
\hline $\begin{array}{l}\text { Augsburg } \\
(2014)[1]\end{array}$ & $\begin{array}{l}\text { unknown, } \\
\text { - tolerance of ideas opposed to one's } \\
\text { own, } \\
\text { · curiosity about and willingness to } \\
\text { learn from other disciplines, } \\
\text { - adaptability, } \\
\text { - openness of mind, } \\
\text { - creativity, } \\
\text { - good communication and listening } \\
\text { skills, } \\
\text { - capacity to absorb information, } \\
\text { - teamwork, } \\
\text { - the ability to look beyond one's own } \\
\text { disciplinary boundaries, } \\
\text { - the capacity for disciplined self- } \\
\text { reflexivity, } \\
\text { - the ability to reflect on knowledge } \\
\text { integration processes, and } \\
\text { - the ability to take on new ideas. }\end{array}$ \\
\hline $\begin{array}{l}\text { Bernstein } \\
(2015)[2]\end{array}$ & $\begin{array}{l}\text { - think in a complex, interlinked } \\
\text { manner, } \\
\text { - think laterally, imaginatively, and } \\
\text { creatively, and } \\
\text { - integrate one's knowledge with the } \\
\text { knowledge of others. }\end{array}$ \\
\hline
\end{tabular}

More traits than those in Table 1 are mentioned in the literature $[8,31,32]$. In particular, Remington-Ducette and Musgrave [25] describe interpersonal competence as a component of transdisciplinarity, and, as part of this competence, include the characteristic of empathy. Walther et al. [29] report a model of empathy in engineering practice that includes traits of self and other awareness, affective sharing, perspective-taking, and emotional regulation. Interestingly, Lonngren et al. [16] identify perspective-taking characteristics such as depth, coverage, and complexity, as key to the skill-set needed to successfully address WSPs.

There are multiple approaches to structuring and assessing connections between cognitive development and transdisciplinary learning. For example, according to Kitchener [12], there are three levels of cognitive processing when one is faced with ill-structured problems, namely cognition; metacognition; and epistemic cognition. In this continuum, we are interested in how to structure and assess learners' levels of cognition such that the development of cognition depth is supported. When ill-structured problems are transdisciplinary, we become aware of another developmental trajectory that may be overlaid, such as those developmentalism concepts constructed in the intercultural competency research [5]. A vast realm of literature on the subject of intercultural sensitivity is available. For example, Bennett's theory draws the individual process of intercultural understanding as a continuum of six different levels: denial, defense, minimization, acceptance, adaptation and integration [10].

\subsection{Metacognition}

As described by Schraw and Dennison [26], "metacognition refers to the ability to reflect on, understand, and control one's learning". People possessing high metacognitive skills know about their cognitive (i.e. thinking) processes and how they use these processes in order to learn and recall knowledge [33]. Research suggests that metacognition is composed of two related components: metacognitive knowledge and metacognitive regulation.

Metacognitive knowledge can be described as what we know about how we learn (i.e., declarative knowledge), what we know about different learning strategies (i.e., procedural knowledge), and what we know about the environment or conditions that support our learning strategies (i.e., conditional knowledge). Metacognitive regulation, on the other hand, refers to the actions we take in order to learn and recall knowledge. These regulating actions can be described as planning, monitoring, evaluating, strategizing, and debugging. Metacognitive regulation is linked to self-regulated learning (SRL) in that it is more easily observed than direct metacognitive regulation.

Young and Fry [33], Schram and Dennison [26] and others, report correlations between metacognitive knowledge and metacognitive regulation. There may also be a correlation between metacognition and academic performance, as indicated by the work of Lawanto et al. [13], and others.

Development of metacognitive knowledge and regulation skills can be supported in the classroom. For example, structural alignment of course material, collaborative group work (wherein students explain their thinking to peers), instructor modeling of metacognition, and verbal encouragement to metacognate by instructors, help to develop metacognitive skills [28]. Further, activities that emphasize planning steps for problemsolving, and that provide opportunities for checking and revising solutions, also improve metacognition [11]. In engineering education, Borgford-Parnell et al. [4] show that reflection improves metacognition as it relates to design practice; while, Nelson et al. [18] suggest that classroom activities in support of an understanding of intelligence as "constructed", rather than "fixed," improves self-regulation of learning. 


\subsection{Research Questions}

While Borgford-Parnell et al. [4] investigate the influence of metacognition on engineering design skills, we, the authors of this paper, wonder if transdisciplinary skills are influenced by metacognition. In this study, we propose to employ systems thinking (also known as complexity thinking) as a measure of transdisciplinary. We then ask two questions, namely: Can improving metacognitive levels, necessarily improve systems thinking? If so, can we provide early support of transdisciplinarity by helping students improve their metacognition?

According to Frank [9], one of the cognitive characteristics of engineers with high capacity for engineering systems thinking includes their ability to understand the system from multiple perspectives, i.e., seeing beyond one's disciplinary framework, which is one of the transdisciplinary skills [1]. We argue that a correlation between systems thinking and metacognition will lead to the development of tools to structure and assess transdisciplinarity in a first year engineering course. Here, we follow the definition of transdisciplinarity offered by Bernstein [2], and specifically the transdisciplinary skill to think in a complex, interlinked, manner. We do so for two reasons:

1. we aim to develop systems thinking in first year engineering students because, like (other) transdisciplinary skills, it is critical to addressing WSPs;

2. unlike many transdisciplinary skills mentioned in Section 1.1 above, we believe that levels of systems thinking are measureable.

\section{METHODOLOGY}

The study reported in this paper is motivated by two hypotheses:

1. systems thinking and metacognition are correlated,

2. activities that enhance metacognition help to improve systems thinking and vice versa.

We have chosen to explore systems thinking and metacognition because assessments exist enabling concrete measures of these two thinking skills. Here, we present methods of measuring systems thinking and metacognitive awareness, and, using these methods, we present an initial exploration of the first hypothesis.

\subsection{Measuring Systems Thinking}

Wiek et al. [31] define systems thinking as the ability to analyze complex systems across different domains (e.g. society, environment, economy), at different scales, CEEA17; Paper 094

University of Toronto; June 4-7, 2017 including the identification of system components, dynamics, cross-cutting influences, and other system features related to sustainability, such as perceptions, motives, and decisions. We propose that concept maps illustrate systems thinking.

Concept maps are visual representations of knowledge domains consisting of nodes, each displaying a noun (or noun phrase), connected with arrows labeled with a verb (or verb phrase), as illustrated in Fig. 1 [19]. They are typically used in one of three ways:

1. by students to represent either individual or group understanding of a knowledge domain,

2. by educators to graphically represent knowledge domains to students,

3. by educators as a tool to assess student understanding of a knowledge domain.

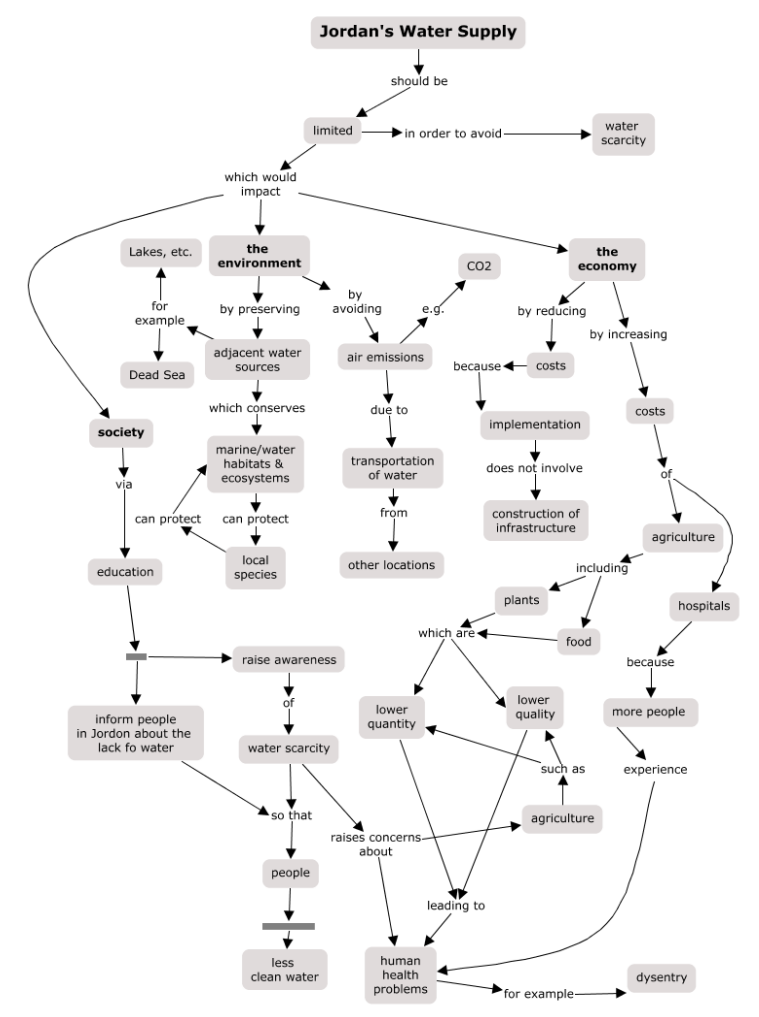

Fig. 1. Example of a concept map created by an engineering student from the focus question relating to the WSP of Jordan's water supply (created with CmapTools Vers. 6.02).

Advantages to representing knowledge in concept maps rather than prose include emphasizing relationships between concepts, and patterns of relationships among concepts [19]. It is reported that concept map utility for assessment has been evaluated across many fields of study. There is significant evidence [19] that, within university education, concept map assessments have high interrater reliability, correlate moderately with other 
assessments, and are sensitive to knowledge gains resulting from instruction.

Relating to engineering education, Besterfield-Sacre et al. [3] showed that concept maps are valid assessment tools of engineering student performance. Watson et al. [30] evaluated the efficacy of three concept map scoring methods, namely the traditional, holistic, and categorical [27] methods. Each scoring method has its strengths. In the case of the traditional method, which quantifies the number of concepts, levels within hierarchies, and number of cross-links between hierarchies, the method's strength is a relatively quick assessment time. Watson et al. corroborate other concept map scoring investigations by finding all three scoring methods possess acceptable interrater reliability and convergent/divergent validity.

To measure student levels of systems thinking, we first give students a mini-lesson on concept map construction reflecting the procedure developed by Novak and Canas [20]. Next, we present students with a paragraph describing a WSP case study which was developed by Lonngren et al. [14]. As per the Lonngren et al. study, students are also presented with six possible responses to the case study and are asked to choose one of the six as the best. They are then asked to construct a concept map given the following focus question:

- What should be considered in order to successfully implement the solution you have chosen?

Each student map (an example of which is provided in Fig. 1) is scored according to the method [21] described as "traditional" by Watson et al. [30]. A single score for the concept map is computed using the following relationship:

$\mathrm{Cmap}=$ Total Score $=(\mathrm{NC}-\mathrm{NCL})+5 \times \mathrm{HH}+10 \times \mathrm{NCL}$ where:

$\mathrm{NC}=$ number of concept nodes

NCL = number of cross-links (between hierarchies)

$\mathrm{HH}=$ number of levels in the largest (i.e. highest) hierarchy

The Cmap score described above reflects the rubric shown in Table 2.

Table 2: Rubric for the Traditional Scoring Method of Concept Maps

\begin{tabular}{|c|c|}
\hline Knowledge & Expectation \\
\hline $\begin{array}{c}\text { Knowledge } \\
\text { Breadth }\end{array}$ & $\begin{array}{l}\text { - The number of concepts included in } \\
\text { the concept map is counted } \\
\text { co consideration given to quality or } \\
\text { correctness of concepts }\end{array}$ \\
\hline
\end{tabular}

\begin{tabular}{|c|c|}
\hline & $\begin{array}{l}\text { - The number of hierarchies (defined } \\
\text { by propositions that include the } \\
\text { concept map topic) included in the } \\
\text { concept map is counted } \\
\text { Depth }\end{array}$ \\
$\begin{array}{c}\text { - The highest level of hierarchy } \\
\text { (number of concepts in the longest } \\
\text { path down a hierarchy) is recorded }\end{array}$ \\
\hline Knowledge & $\begin{array}{l}\text { - The number of cross-links, which } \\
\text { create propositions using concept } \\
\text { from different hierarchies, is } \\
\text { counted. } \\
\text { Connectedness } \\
\text { No consideration generally given to } \\
\text { quality or correctness of cross-links. }\end{array}$ \\
\hline
\end{tabular}

\subsection{Measuring Metacognitive Awareness}

The Metacognitive Awareness Inventory (MAI) is an assessment instrument aimed at measuring a student's level of metacognitive knowledge and regulation. Developed in 1994 by Schraw and Dennison [26], and consisting of 52 statements each of which the respondent is asked to either agree or disagree, it is acknowledged in the literature as a reasonable, easy-to-use tool providing a reliable measure of a student's metacognitive levels. Each statement relates to an aspect of metacognition, i.e., either metacognitive knowledge or metacognitive regulation. The total MAI score is the sum of the number of statements with which the respondent agrees, so that the maximum score on the MAI instrument is 52 .

\subsection{First Version of the Data Collection Protocol}

The following describes the data collection protocol developed to measure systems thinking and metacognition in UBC's first year engineering cohort which consists of approximately 800 students. This paper reports a test of the data collection protocol, performed in March 2017, aimed at determining the protocol's strengths and weaknesses.

APSC 101 is a first year, design-focused, flippedclassroom, course that has been offered to engineering students since January 2015. The course consists of two classes of 50 minutes and one 2-hour studio session each week. Approximately 60 students are in each studio section.

To obtain Cmap and MAI data from the first year engineering cohort, the following steps were completed:

1. a written announcement of the study was provided to each studio instructor, who then informed students of the opportunity to volunteer in the study. The announcement included:

a. a date and time for the study's workshop (which included data collection activities
CEEA17; Paper 094

University of Toronto; June 4 - 7, 2017
-4 of $8-$ 
and a pizza and pop lunch),

b. the list of authors of the study, and

c. a broad description of the purpose of the study.

Students were told to expect an e-mail later that day with more details.

2. After the studio session announcement, students received an e-mail containing the same information that was read out in the studio session along with a request to those interested in participating, to complete an anonymous sign-in sheet.

3. The workshop consisted of:

a. a mini-lesson on concept map construction (approx. 15 minutes)

b. deployment of the concept map exercise (approx. 30 to 45 minutes)

c. deployment of the MAI (approx. 10 minutes)

4. Those who attended the workshop were each given a small gift certificate in recognition of their giving time to attend the workshop.

Of the fifteen first year students who signed up for the mid-March 2017 workshop, four participated. Because of this low number, and in order to further test the data collection protocol, data was also collected from second year students. In this case, one of the authors attended a class of approximately twenty students, during which the intent and conditions of the study were explained and students were asked to participate during class time. Those who did not wish to participate were excused from the class; seventeen of the twenty students kindly stayed and completed the concept mapping and MAI tasks. The instructor for the class was not present therefore interactions between the visiting author and the students were anonymous. Workshop steps " $3 b$ ", and " $3 c$ " described above were then deployed. The second year students had previously studied concept map construction skills, therefore, instead of step " $3 \mathrm{a}$ " described above, students were briefly reminded of the steps involved in concept map construction.

\section{RESULTS AND ANALYSIS}

Data collected from both the four first year students and the seventeen second year students are presented in Fig. 2. Analysis of this preliminary data set suggests the Pearson correlation coefficient between Cmap and MAI scores may be weak but positive (for the preliminary data it is 0.154 , with a 2 -tailed sig. $=0.506$ ).

Further, Fig. 3 suggests that first year students may have a weaker variation in Cmap score (std. dev.=11.6) than second year students (std. dev. $=24.7$ ). Also, these preliminary data indicate that the second year students may have outperformed the first year students in Cmap scores (Hedge's $\mathrm{g}=0.49$, medium effect), and in MAI $(\mathrm{g}=0.59$, medium effect). However, the small sample size $(\mathrm{N}=21)$ means that no conclusions can be made.

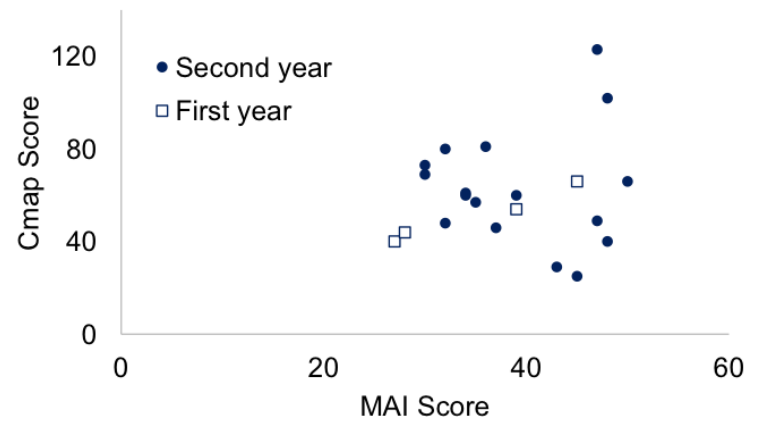

Fig. 2. Data collected to date. Individual students are shown with their Cmap Score plotted versus their MAI Score.

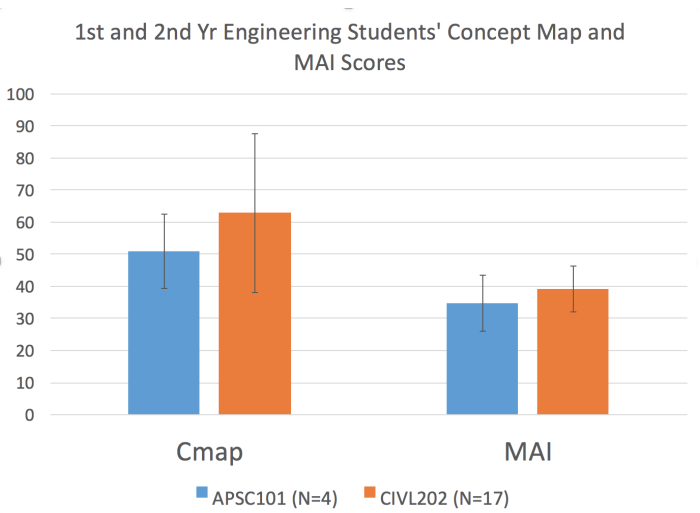

Fig. 3. A comparison between first year and 2 nd year Cmap and MAI scores, showing st. dev. as error bars.

\section{DISCUSSION AND NEXT STEPS}

The following sections discuss the data collection protocol, preliminary results, and next steps to be followed in 2017-2018.

\subsection{Discussion of Data Collection and Analysis}

The test of data collection procedures reported here highlight significant challenges. Low first year student recruitment numbers are concerning. It may be that a data collection workshop (including pizza and pop) taking place only two weeks prior to the university's examination period, is simply bad timing. Further, it may be that students do not perceive a studying advantage to the workshop. The high participation of second year students may indicate that the use of APSC 101 instructional time for data collection could greatly increase first year participation rates.
CEEA17; Paper 094

University of Toronto; June 4 - 7, 2017 
A higher quality of first year student concept maps compared to those of second year students is evident by visual inspection of maps. That is, while the first year student maps are well organized, with clear identification of nouns (or noun phrases), verb-labelled arrows, and cross-links, seven of the seventeen second year student maps are missing at least some verb-labels. Of these, one concept map is missing all arrows connecting different concept nodes. This observed difference in maps may be due to the quality of the mini-lesson provided just prior to first year students completing their systems-thinking task.

Concept map analysis time is a critical component of a study involving hundreds of students. During analysis of the preliminary data presented here, we found that concept map evaluation required training time for the evaluator to ensure consistent results (approximately 45 minutes) and approximately 5 minutes to score the work of each student. Ensuring concept map scoring consistency while minimizing the time and cost of the scoring process is an important part of future work.

Finally, a deeper concern exists regarding our preliminary work: our measuring of transdisciplinary skills may warrant strengthening. Assessment techniques described in the transdisciplinary literature (for example see $[31,25]$ generally rely on the detailed and timeconsuming assessment of written work using a carefully constructed marking rubric. To avoid long assessment times, we chose here to focus on systems thinking as measured by Cmap scores. We argue that systems thinking is a transdisciplinary skill. But other ways of thinking are also part of the transdisciplinary skill-set. In addition to, or perhaps instead of, systems thinking, it would be ideal to quantify the personal values, and empathetic level of students.

\subsection{Discussion of Preliminary Results}

Although the sample sizes are small, intriguing observations can be made about the preliminary data. A weak but positive correlation is noted between MAI and Cmap scores, suggesting systems thinking and metacognition may indeed be correlated. In particular, the four first year students' scores correlate strongly $(\mathrm{r}=$ $0.984, p=0.016$ ). However, considering the very small sample size and the distribution of second year students' scores, it is hard to imagine that these findings are not largely the result of chance. At the same time, the first year students received additional instruction on the creation of concept maps, so we cannot dismiss the possibility that a higher degree of correlation has been observed as a result of this training. That is, the minilecture for second year students was much shorter than that given to first year students. In part this was due to time constraints in the second year classroom, but, also, it was assumed that, because the second year students had studied concept map construction earlier in the term, only a brief reminder of concept map construction steps was required.

\subsection{Future Explorations}

The preliminary work presented in this paper aids the generation of an improved data collection protocol that we intend to deploy in the 2017-2018 academic year. Our next steps include:

1. Design an instructional intervention aimed at improving student metacognition. The intervention may involve student reflection on design activities performed earlier in the APSC 101 course.

2. Collect transdisciplinary data and MAI data before and after deployment of the instructional intervention.

3. Expand the measures used to assess transdisciplinarity by incorporating or adapting the Intercultural Sensitivity Index (ISI), which reflects such domains as personal values, respect and empathy with others, and integrating values of others while keeping one's own [23], or perhaps by adding the "Neuroticism, Extraversion, and Openness-to-Experience" Personality Inventory (NEO-PI [17]. Collecting Cmap and data related to the ISI or NEO-PI will capture breadth in transdisciplinary skills.

4. Collect a relatively small sample of concept maps and thereby limit the cost of concept map analysis. For example, by collecting a large number of ISI data, we can de-emphasize Cmap scores.

5. Improve data collection:

a. collect quantitative data during instructional time

b. provide students with a concept map mini-lesson just prior to completing the concept map task

c. train concept map evaluators to maximize interrater reliability.

6. Convene focus groups as part of the data collection process. This may guide the data collection protocol and will enable deeper interpretation of the quantitative data.

This paper does not offer a detailed discussion of the metacognition learning intervention mentioned in item 1 of the above. However, generally speaking, we envision this intervention to be a series of reflection activities, each linked to specific design assignments and each focused on students exploring both the types of mistakes made in

CEEA17; Paper 094

University of Toronto; June 4-7, 2017 
their assignments and their level of confidence in knowledge of the design concepts assessed by the assignment.

\section{SUMMARY and CONCLUSION}

The need for engineering students to successfully address and manage WSPs with others, raises the complex question of how best to develop and teach constructively aligned transdisciplinary skills. To address this question, we propose that transdisciplinarity, as measured by systems thinking, is positively correlated with metacognition, and that learning metacognitive skills can be used a first step to developing transdisciplinarity.

A data collection protocol, using concept maps to measure systems thinking and the MAI to measure metacognition, is described and a test of this protocol is presented. Analysis of the test data yielded results that are tantalizing, though not statistically significant, and deploying the data collection protocol stimulated improvements to future data collection activities such as:

- collecting data during instructional time rather than during a data collection workshop;

- measuring more than one transdisciplinary skill (i.e. measuring systems thinking via concept map data and measuring empathy via the Intercultural Sensitivity Index); and

- convening focus groups to gain insights into the student learning experience.

During the 2017-2018 academic year, we, the authors, plan to develop metacognitive learning interventions for the first year engineering course, then deploy the improved data collection protocol to measure the influence of these interventions on both metacognitive and transdisciplinary skills.

\section{ACKNOWLEDGEMENTS}

The authors are very grateful to Ms. Tanya Tan who performed data analysis work. We also thank Dr. Patricia Keen who invited us into a section of her 2nd year engineering class, and the APSC 101 Studio Instructors, who participated in learner recruitment as described in Section 2.3 of this paper.

We also recognize the University of British Columbia Teaching and Learning Enhancement Fund (TLEF), which provided funding to redesign the first year curriculum and introduce the new APSC 100 and 101 courses.

Finally, we acknowledge and thank the first and second year engineering student volunteers who gave their time so that learning opportunities of future students might be improved.

\section{REFERENCES}

[1] Augsburg, T. (2014) "Becoming transdisciplinary: The Emergence of the Transdisciplinary Individual", World Futures, 70, 233-247. http://dx.doi.org/10.1080/02604027.2014.934639

[2] Bernstein, J. (2015) "Transdisciplinarity: a review of its origins, development, and current issues", Journal of Research Practice, 11(1), 17 pages.

[3] Besterfield-Sacre, M., Gerchak, J., Lyons, M.R., Shuman, L.J., Wolfe, H. (2004) "Scoring concept maps: an integrated rubric for assessing engineering education", Journal of Engineering Education, 93(2), 105-115.

[4] Borgford-Parnell, J., Deibel, K., Atman, C.J.(2010) "From engineering design research to engineering pedagogy: bringing research results directly to the students", International Journal of Engineering Education, 26(4), 748-759.

[5] Chen, G. (1997). "Review of the concept of intercultural sensitivity". Pacific and Asian Communication, 1-13.

[6] del Cerro Santamaria, G. (2015) "Transdisciplinary technological futures: an ethnographic research dialogue between social scientists and engineers", Technology in Society, 40, 53-63.http://dx.doi.org/10.1016/j.techsoc.2014.10.005

[7] Ellis, N., Nesbit, S., Ostafichuck, P., Sibley, J. (2016) “A sustainability retrofit of engineering undergraduate education Phase 2", Proc. 8th Conf. on Engineering Education for Sustainable Development. Sept. 4-7, Bruges, Belgium, 235-242.

[8] Fortuin, K.P.J. \& van Koppen, C.S.A. (2015) “Teaching and learning reflexive skills in inter- and transdisciplinary research: a framework and its application in environmental science education", Environmental Education Research. 22(5), 697 716. http://dx.doi.org/10.1080/13504622.2015.1054264

[9] Frank, M. (2006) "Knowledge, abilities, cognitive characteristics and behavioral competences of engineers with high capacity for engineering systems thinking (CEST)", Systems Engineering, 9(2), 91-103.

[10] Hammer, M. R., Bennett, M. J., \& Wiseman, R. (2003). "Measuring intercultural sensitivity: the intercultural development inventory". International Journal of Intercultural Relations, 27(4), 421-443. http://doi.org/10.1016/S01471767(03)00032-4

[11] Hollingworth, R.W., McLoughlin, C. (2001) "Developing science students' metacognitive problem solving skills online", Australian Journal of Educational Technology, 17(1), 50-63.

[12] Kitchener, K. S. (1983). "Cognition, metacognition, and epistemic cognition”. Human Development, 26, 222-232. [13] Lawanto, O., Butler, D., Cartier, S., Santoso, H.B., Goodridge, W. (2013) "Task interpretation, cognitive, and metacognitive strategies of higher and lower performers in an
CEEA17; Paper 094

University of Toronto; June 4 - 7, 2017 
engineering design project: an exploratory study of college freshman", International Journal of Engineering Education, $29(2), 459-475$.

[14] Lonngren, J., \& Svanstrom, M. (2015) Assessing ““"Wicked sustainability problems" Literacy in Engineering Education", Conference Proceedings of ASEE 2015, June 14-17, Seattle Washington.

[15] Lonngren, J., Ingerman, A., Svanstrom, M. (2016) “Avoid, control, succumb, or balance: engineering students' approaches to a wicked sustainability problem", Research in Science Education, (July 09), 27 pages.

[16] Lonngren, J., Svanstrom, M., Ingerman, A., Holmberg, J. (2015) "Dealing with the multidimensionality of sustainability through the use of multiple perspectives - a theoretical framework", European Journal of Engineering Education, 3797, pp 1-11. http://dx.doi.org/10.1080/03043797.2015.1078911

[17] McCrea, R., Costa, P.T. (1991) "The neo personality inventory: using the five-factor model in counseling", Journal of Counseling \& Development, 69(4), 367-372.

[18] Nelson, K.G., Shell, D.F., Husman, J., Fishman, E.J., Soh, L.-K. (2015) "Motivational and self-regulated learning profiles of students taking a foundational engineering course", Journal of Engineering Education, 104(1), 74-100.

[19] Nesbit, J., \& Adesope, O. (2013) "Concept maps for learning: theory, research and design", Chpt 12 in Learning Through Visual Displays (ed.s G. Schraw, M. T. McCrudden, D. Robinson), IAP Information Age Publishing, Charlotte, NC.

[20] Novak, J.D. \& Canas, A.J. (2006) "The theory underlying concept maps and how to construct and use them", Technical Report, Institute for Human and Machine Cognition. http://cmap.ihmc.us/docs/theory-of-concept-maps

[21] Novak and Gowin (1984) Learning how to learn. Cambridge University Press, New York, NY. as attributed in Watson, M.K., Pelkey, J., Noyes, C.R., Rodgers, M.O. (2016) "Assessing conceptual knowledge using three concept map scoring methods", Journal of Engineering Education 105(1), 118-146.

[22] Ostafichuk, P., Jeager, C., Nakane, J., Nesbit, S., Ellis, N., Sibley, J. (2016) "Redesigning the ubc first year introduction to engineering: successes and challenges", Proc. 2016 Canadian Engineering Education Association Conf., June 19-22, Halifax, Nova Scotia. 8 pages.

[23] Paige, R. M., Jacobs-Cassuto, M., Yershova, Y. A., \& DeJaeghere, J. (2003). "Assessing intercultural sensitivity: an empirical analysis of the Hammer and Bennett Intercultural Development Inventory". International Journal of Intercultural Relations, 27(4), 467-486. http://doi.org/10.1016/S0147-1767(03)00034-8
[24] Poole, G. (2009) “Academic disciplines: homes or barricades?", Chpt. 4 in The University and its Disciplines: Teaching and Learning Within and Beyond the Disciplinary Boundaries. (ed. C. Kreber), Taylor and Francis, New York.

[25] Remington-Doucette, S. \& Musgrove, S. (2015) "Variation in sustainability competency development according to age, gender, and disciplinary affiliation: implications for teaching practice and overall program structure", International Journal of Sustainability in Higher Education, 16(4), 537-575. http://dx.doi.org/10.1108/IJSHE-01-2013-0005

[26] Schraw, G. \& Dennison, R.S. (1994) “Assessing metacognitive awareness", Contemporary Educational Psychology, 4, 460-475.

[27] Segalàs, J., Ferrer-Balas, D., Mulder, K. F. (2008) "Conceptual maps: measuring learning processes of engineering students concerning sustainable development", European Journal of Engineering Education, 33(3), 297-306. http://dx.doi.org/10.1080/03043790802088616

[28] Wagaba, F., Treagust, D.F., Chandrasegaran, A.L., Won, M. (2016) "Using metacognitive strategies in teaching to facilitate understanding of light concepts among year 9 students", Research in Science \& Technological Education, 34(3), 253-272.

http://dx.doi.org/10.1080/02635143.2016.1144051

[29] Walther, J., Miller, S.E., Sochacka, N.W. (2017) “A model of empathy in engineering as a core skill, practice orientation, and professional way of being", Journal of Engineering Education, 106(1), 123-148. doi/10.1002/jee.20159/abstract

[30] Watson, M.K., Pelkey, J., Noyes, C.R., Rodgers, M.O. (2016) "Assessing conceptual knowledge using three concept map scoring methods", Journal of Engineering Education 105(1), 118-146. /doi/10.1002/jee.20111/abstract

[31] Wiek, A., Withycombe, L. and Redman, C.L. (2011) "Key competencies in sustainability: a reference framework for academic program development", Sustainability Science, 6(2), 203-218. doi/10.1007/s11625-011-0132-6

[32] Wiek, A., Bernstein, M., Foley, R., Cohen, M., Forrest, N., Kuzdas, C., Kay, B. and Withycombe Keeler, L. (2015) "Operationalising competencies in higher education for sustainable development", Handbook of Higher Education for Sustainable Development, (ed.s M. Barth, G. Michelsen, M. Rieckmann, I. Thomas), Routledge, London, pp. 241-260.

[33] Young, A. \& Fry, J.D. ( 2008) "Metacognitive awareness and academic achievement in college students", Journal of the Scholarship of Teaching and Learning, 8(2), 1-10.
CEEA17; Paper 094

University of Toronto; June 4 - 7, 2017 